\title{
Atuação dos projetos de mecanismo de desenvolvimento limpo para o desenvolvimento sustentável no Brasil
}

\author{
Performance of clean development mechanism \\ projects for sustainable development in Brazil
}

ELAINE APARECIDA FERNANDES*

GUSTAVO BARROS LEITE**

RESUMO: Este estudo buscou analisar, para o caso brasileiro, o Mecanismo de Desenvolvimento Limpo (MDL). Usou-se o conceito de externalidade negativa e falha de mercado para entender a necessidade de políticas ambientais capazes de favorecer o desenvolvimento sustentável dos países. Os resultados mostraram a importância da escala para o registro de projetos. O setor de energia, por exemplo, tem mais projetos de pequena escala que foram criados para simplificar os procedimentos e diminuir os custos. Concluiu-se, de forma geral, que o MDL se tornou um marco histórico internacional, pois é uma ferramenta de caráter inovador na contribuição à mitigação das mudanças climáticas. Contudo, apesar de sua importância ser reconhecida globalmente, observou-se que o mecanismo foi se enfraquecendo com o passar do tempo e há incertezas a respeito da vigência do Protocolo de Quioto.

PALAVRAS-CHAVE: Mecanismo de Desenvolvimento Limpo; protocolo de Quioto; desenvolvimento sustentável; Brasil.

ABSTRACT: This paper analyzed, for the Brazilian case, the Clean Development Mechanism (CDM). The concept of negative externality and market failure was used to understand the need for environmental policies capable of favoring the sustainable development of countries. The results show the importance of scale for the registration of projects. The energy sector, for example, has more small-scale projects that were created to simplify procedures and lower costs. It was concluded, in general, that the CDM has become an international historical landmark, as it is an innovative tool in contributing to the mitigation of climate

\footnotetext{
* Universidade Federal de Viçosa, Viçosa/MG, Brasil. E-mail: eafernandes@ufv.br. Orcid: https://orcid. org/0000-0002-3503-7036.

** Universidade Federal de Viçosa, Viçosa/MG, Brasil. E-mail: Gustavo.b.leite@ufv.br. Orcid: https:// orcid.org/0000-0001-9103-107X. Submetido: 6/Abril/2020: Aprovado: 8/Junho/2020.
} 
change. However, despite its importance being recognized globally, it was observed that the mechanism has weakened over time and there are uncertainties regarding the validity of the Kyoto Protocol.

KEYWORDS: Clean Development Mechanism; Kyoto protocol; sustainable development; Brazil.

JEL Classification: Q01.

\section{INTRODUÇÃO}

O Mecanismo de Desenvolvimento Limpo (MDL), através do mercado de carbono, foi projetado para oferecer dupla vantagem: para o comprador/país desenvolvido pode ser mais vantajoso e barato pagar um projeto de investimento em um país em desenvolvimento do que alterar o seu processo produtivo já consolidado; e, principalmente, para o vendedor/país em desenvolvimento, pode-se ter benefícios ambientais com a diminuição de emissões, benefícios financeiros com a venda dos créditos de carbono e benefícios sociais com a promoção do desenvolvimento sustentável (Brasil, 2010; Godoy, 2009).

O Brasil se insere nesse contexto com grande potencial para investimento em projetos de MDL. O país foi o primeiro a assinar a Convenção das Nações Unidas sobre Mudança do Clima (CNUMC), em 1992, e de forma voluntária propôs sua participação na mesma por meio de projetos do MDL (Magalhães, 2013). O país ainda foi o primeiro a registrar um projeto MDL da história, portanto, além de suas características físicas que possibilitam desenvolvimento em vários setores, principalmente o de energia limpa, o Brasil se mostra um dos países mais atuantes na área, sendo o terceiro com mais projetos registrados, atrás apenas da China e Índia (Dechezleprêtre, Glachant, Ménière, 2009). Este fato motivou o presente estudo que pretende responder às seguintes perguntas: 1) Que tipo de setores, no Brasil, tem recebido mais projetos de MDL? 2) Estes projetos são de pequena ou grande escala? 3) Existem muitos projetos rejeitados ou o Brasil tem conseguido aprovar projetos de MDL no Conselho Deliberativo?

Desde sua criação, o Mecanismo de Desenvolvimento Limpo tem sido fonte de estudos que visam avaliar seu desempenho juntamente com o desenvolvimento dos mercados de carbono. Trabalhos apontam que a contribuição do MDL para o desenvolvimento sustentável tem sido limitada (Capoor e Ambrosi, 2006; Ellis et al., 2007; Sutter e Parreño, 2007; Pasini e De Andrade Spínola, 2011), onde na maioria dos casos o MDL não foi o principal motivador (Guillen, 2010), se tornando fonte de muitas críticas. Por outro lado, há estudos que comprovam as contribuições para o desenvolvimento sustentável (He, Huang e Tarp, 2014; BAYER et al., 2013). Voltado para o Brasil, tem-se artigos que buscam relacionar o impacto do MDL na geração de emprego e na geração de renda e redução da pobreza em nível municipal (Mori-Clement, Bednar-Friedl, 2019; Mori-Clement, 2019).

Todavia, visto o número de críticas, alguns autores identificam a importância e potencial do mecanismo e buscam opções de melhorias através da reforma do 
sistema (Schneider, 2007; Boyd et al., 2009; Souza e Corazza, 2017). O mercado de carbono e os mecanismos de mercado implantados são considerados ainda muito novos, passando constantemente por mudanças que, na maioria das vezes, são de difícil entendimento do público devido à linguagem técnica aplicada, além da falta de uma ampla divulgação das informações. Ao se considerar que o final do segundo período (2013-2020) do tratado está no fim, o objetivo deste trabalho é apresentar a evolução do seu principal mecanismo, o MDL, principalmente no Brasil, analisando onde e como seu desempenho tem ocorrido no país, associando algumas das suas principais características: escala, status e distribuição por tipo.

Não foram encontrados na literatura nenhum trabalho que abrangesse análises e dados tão recentes quanto os utilizados no presente estudo.

Além desta introdução, o trabalho contém mais quatro seções. A próxima faz uma revisão teórica e empírica sobre o tema; a terceira ilustra a metodologia utilizada; a quarta mostra os resultados e discussão; e, a última, trata das conclusões obtidas.

\section{EXTERNALIDADES, DESENVOLVIMENTO SUSTENTÁVEL E MDL}

\section{Externalidades e os gases do efeito estufa (GEE)}

Uma externalidade negativa, ou custo externo, existe quando a atividade de um agente causa perda de bem-estar a outro agente e quando esta perda não é compensada (Pearce e Turner, 1990). Este custo externo não é desembolsado pela unidade produtiva, logo, o custo subestimado faz com que o nível de produção da empresa e, consequentemente, da indústria fique acima do nível de produção ótimo.

No presente trabalho, as emissões de GEE implicam uma externalidade transfronteiriça negativa, pois a emissão em um determinado país irá se alastrar por toda a atmosfera, que é um bem público, ou seja, não-rival e não-exclusivo. $\mathrm{O}$ aumento da concentração de gás carbônico, por sua vez, gera a perda de bem-estar da sociedade.

Portanto, a externalidade gerada pelas emissões de GEE ainda é persistente, o efeito cumulativo gerado é de difícil reversibilidade devido à grande concentração ante a baixa taxa de renovação atmosférica. A especificidade do problema supõe uma externalidade também intertemporal, onde gerações futuras serão afetadas por custos gerados no passado. De acordo com Manson (1996), as consequências das externalidades geradas, particularmente as globais, vão recair sobre as gerações futuras.

Além de ser um dos problemas ambientais mais sérios enfrentados atualmente, existe uma complexidade extrema por trás. As fontes de emissão de GEE são mais difusas que qualquer outro problema ambiental, sendo que esses gases, além de gerados por diversas fontes do cotidiano social como empresas, fazendas, transportes, famílias, dentre outros, ainda existe uma variedade ampla de gases que integram a categoria de gases causadores do efeito estufa, sendo que alguns podem permanecer 
na atmosfera por centenas de anos. Portanto, é considerado um problema de longo prazo e com elevado grau de dificuldade de geri-lo (Magalhães, 2013).

Para Bithas et al. (2011), se a política ambiental internalizar as externalidades ambientais, a sustentabilidade pode ser assegurada. Entretanto, esta internalização deve resultar na preservação dos direitos ambientais das gerações futuras em termos ecológicos-biológicos. Nesse sentido, deve-se ressaltar que a violação desses direitos ambientais não pode ser compensada pelas estruturas compensatórias utilitárias tradicionais (Spash, 1993).

\section{Desenvolvimento sustentável}

A partir do século XIX, com a intensificação do processo de industrialização e dos sistemas agropecuários, a demanda por recursos naturais e os danos ao meio ambiente tornaram-se crescentes. Sendo assim, a sociedade teria que explicitamente fazer uma escolha entre desenvolvimento e preservação, e lidar posteriormente com as consequências de sua decisão. A questão era se deveria ou não desacelerar o ritmo de crescimento econômico em função da crescente degradação ambiental.

A partir da década de 1970, entretanto, surge o conceito de desenvolvimento que incorporava a preocupação ambiental. $\mathrm{O}$ marco inicial foi a realização da Conferência das Nações Unidas sobre o Meio Ambiente Humano em Estocolmo (Suécia) em 1972. Representantes de vários países discutiram a problemática ambiental e sua proporção em âmbito global. Nessa Conferência, foram definidas pelos 113 países participantes as diretrizes da política ambiental da ONU para os 20 anos subsequentes e, diante de tal proposta, foi criado o Programa das Nações Unidas para o Meio ambiente (PNUMA). Um dos objetivos principais do PNUMA seria o incentivo às nações de se desenvolver uma legislação ambiental. Criou-se ainda o Fundo Voluntário para o Meio Ambiente que seria gerido pelo PNUMA (Martins, 2006).

Ganha destaque na Conferência o relatório "Limites do Crescimento", elaborado e publicado no ano seguinte por um grupo de cientistas e acadêmicos denominado Clube de Roma. De concepção neomalthusiana, o relatório recebe várias críticas por defender o chamado "crescimento zero" e ignorar as dessemelhanças existentes entre países ricos e pobres quanto aos padrões de consumo dos recursos naturais. Embora os pesquisadores não tivessem proposto que crescimento era o mesmo que desenvolvimento e que "crescimento zero" não implicaria estagnação, o estudo foi bastante criticado. Representantes dos países do terceiro mundo responderam de forma negativa ao então denominado "crescimento zero" e afirmaram que os níveis de consumo não era a causa dos problemas ambientais. Sendo assim, a Conferência de Estocolmo não representou avanços significativos.

O enfoque do "crescimento zero" foi superado e ganha importância crescente o conceito de Desenvolvimento Sustentável. Em 1973, Maurice Strong elaborou a proposta de Ecodesenvolvimento, em que se recomendava a utilização mais racional de ecossistemas locais, valorizando o conhecimento das populações envolvidas no processo produtivo. Esta proposta foi desenvolvida por Sachs em diversos tra- 
balhos (Sachs, 1975, 1990, 1993). O Ecodesenvolvimento procurou se apoiar em cinco dimensões da sustentabilidade: a social, a econômica, a ecológica, a espacial e a cultural. Em resumo, sua ideia é de que o Ecodesenvolvimento deve assumir um enfoque de planejamento de estratégias plurais de harmonização entre as atividades de dinamização socioeconômica e o trabalho de gestão racional do meio ambiente.

A ideia do desenvolvimento sustentável reside na ideia do Ecodesenvolvimento de Sachs e Strong e foi consolidada no Relatório da Comissão Mundial sobre o Meio Ambiente e Desenvolvimento da ONU de 1987 conhecido como "Our Common Future" ou "Relatório Brundtland" e estava centrado em três eixos principais: crescimento econômico, equidade social e equilíbrio ecológico.

Do ponto de vista econômico, o Relatório Brundtland implica duas condições: o desenvolvimento deve permitir a ampliação, ou pelo menos a manutenção, da qualidade de vida em um horizonte temporal longo; e manutenção, ao longo do horizonte temporal, do estoque de capital, incluindo os recursos naturais. Neste relatório, o desenvolvimento sustentável foi definido como o desenvolvimento que satisfaz as necessidades presentes, sem comprometer a capacidade das gerações futuras de suprir suas próprias necessidades (Comissão Mundial Sobre Meio Ambiente e Desenvolvimento, 1988, p. 46). Isso significa que o crescimento econômico deve causar um aumento da renda nacional, mas ser acompanhado também por uma melhora ou pela conservação ambiental.

Essa definição é aceita, desde então, como base do marco teórico inspirador da agenda internacional predominante sobre o tema. Muitos países participaram de sua elaboração, o que certamente ajudou a promover sua grande projeção internacional.

Na década de 1990, a Conferência das Nações Unidas sobre o Meio Ambiente e Desenvolvimento (Eco-92), realizada no Rio de Janeiro, trouxe o tema de volta ao foco da agenda política internacional. Tratava-se, então, de avançar com um conceito de desenvolvimento sustentável bem mais amplo, combinando a preservação ambiental e o uso racional dos recursos naturais com o imperativo da resolução dos problemas sociais.

Nessa Conferência, apesar dos conflitos de interesses presentes, foi elaborado um programa de ação de longo prazo e amplo impacto internacional, a Agenda 21, no qual lançaram-se algumas bases para se praticar, em termos globais, o emergente conceito de desenvolvimento sustentável.

Os resultados da Eco-92 desdobraram-se, em termos de instrumentos de mensuração, a partir de agosto de 1994, com a realização da Conference and Workshop on Indicators of Sustainability - CWIS. Segundo Hart (1994), embora já existissem algumas iniciativas de concepção de metodologias para aplicação de instrumentos de mensuração, a CWIS possibilitou alguns avanços, entre os quais se destacaram: a) reconhecimento de diferentes definições de sustentabilidade; b) necessidade de uma metodologia adequada para o uso efetivo de indicadores de sustentabilidade e; c) constatação do interesse governamental e privado no tema.

Com a realização da CWIS, aumenta-se o interesse em se medir efetivamente o desenvolvimento sustentável. A medida mais comum de desenvolvimento é o Pro- 
duto Interno Bruto (PIB), e muitas são suas limitações (a dificuldade em se distinguir as classes sociais e ignorar se a utilização de recursos é prudente ou não) (Redclift, 1992). Esta lacuna só pode ser preenchida por conhecimentos multidisciplinares. Em 1996, a Comissão para o Desenvolvimento Sustentável das Nações Unidas publicou metodologias para diversos indicadores. Nos anos de 2002 e 2004, foram lançados os primeiros indicadores brasileiros de desenvolvimento sustentável pelo IBGE. Não existe ainda um único indicador que seja suficientemente descritivo quanto à sustentabilidade do desenvolvimento. As publicações compreendem sempre diversos indicadores para os diferentes aspectos observados. No entanto, foram desenvolvidas ferramentas que compilam os indicadores e avaliam o desenvolvimento sustentável, dentre elas três se destacam: o Método da "Pegada Ecológica", o Barômetro de Sustentabilidade e o Painel de Sustentabilidade.

É importante ressaltar que estes sistemas de indicadores foram selecionados como os mais reconhecidos e promissores na atualidade por uma amostra internacional de especialistas que atuam em diferentes esferas da sociedade e que trabalham com o conceito de desenvolvimento sustentável. Para maiores informações, pode-se consultar Rees e Wackernagel (1996). Estes autores fornecem uma visão detalhada a respeito dos conceitos e aplicações dos sistemas de indicadores.

Ao considerar o conceito de desenvolvimento sustentável baseado nos aspectos econômico, ambiental e social, o presente trabalho tratou dos dois primeiros aspectos buscando discutir a sustentabilidade ambiental no desenvolvimento brasileiro atual e quanto às suas expectativas futuras. Como se pode notar, a sustentabilidade ambiental engloba diversos fatores e, por uma necessidade de especificação, o fator a ser observado aqui é a concentração de gás carbônico na atmosfera.

\section{Mecanismo de Desenvolvimento Limpo}

O MDL nasceu de uma sugestão brasileira da criação de um fundo de desenvolvimento, onde os países do Anexo I que não cumprissem suas metas de redução de emissões de gases de efeito estufa deveriam pagar uma multa que seria destinada para o Fundo de Desenvolvimento Limpo, servindo de apoio a projetos de mitigação dos GEE. Os países industrializados foram contra esse tipo de sistema punitivo, mas propuseram um sistema baseado no mercado para ajudar a cumprir seus compromissos assumidos de redução. Os países em desenvolvimento concordaram com a ideia, desde que o desenvolvimento sustentável se tornasse uma meta principal do mecanismo (Figueres, 2006).

Como já definido no Artigo 12 do Protocolo de Quioto, o Desenvolvimento

Sustentável, assim como a redução das emissões dos GEE, são os principais objetivos do Mecanismo de Desenvolvimento Limpo. Para Santin (2007), o MDL estimula países em desenvolvimento a criarem métodos sustentáveis de produção capazes de gerar Redução Certificadas de Emissão (RCEs) ou créditos de carbono, e se tornando posteriormente passíveis de comercialização. Consequentemente, incita o desenvolvimento sustentável do país, paralelamente com a contenção de emissões dos GEE. 
É incorporado dentro dessa relação dos países do Anexo I ${ }^{1}$ e os em desenvolvimento a ideia de um salto tecnológico, onde os países já desenvolvidos ajudariam aqueles em desenvolvimento a pularem algumas etapas no processo de desenvolvimento, seja através de transferência tecnológica ou de financiamento em projetos de substituição de energia fósseis por renováveis, racionalização do uso da energia, reflorestamento, dentre outros.

Um dos requisitos para que um país possa participar de projetos de MDL é que ele estabeleça e nomeie uma Autoridade Nacional Designada (AND), pois apenas o país que sedia tais projetos seria capaz de julgar e avaliar a contribuição do projeto segundo seus próprios requisitos e entendimento de desenvolvimento sustentável. Ou seja, a AND é a entidade que emite a carta de aprovação do projeto no âmbito nacional (Lazaro e Gremaud, 2007). Porém, a falta de uma definição internacionalmente aceita do conceito de desenvolvimento sustentável faz com que haja ambiguidade em relação à participação do MDL para o desenvolvimento sustentável.

No Brasil tem-se a Comissão Interministerial de Mudança Global do Clima (CIMGC) como responsável por analisar os projetos, sendo comandada pelo Ministério da Ciência, Tecnologia, Inovações e Comunicações e formada por representantes de variados ministérios do governo. Essa comissão estabeleceu os seguintes aspectos de contribuição dos projetos para o desenvolvimento sustentável local: contribuição para a sustentabilidade ambiental local; contribuição para o desenvolvimento das condições de trabalho e a geração de emprego; para a distribuição de renda; o desenvolvimento tecnológico e para integração regional (BRASIL, 2019).

Em relação ao MDL, é interessante entender o processo necessário para que o projeto transforme a mitigação dos GEE em unidades de créditos de Redução Certificadas de Emissão (RCE), onde cada crédito equivale a uma tonelada de $\mathrm{CO}_{2}$ ou outro gás equivalente. Para isso, as atividades devem passar por sete etapas de avaliação e monitoramento:

$1^{a}$ Elaboração do Documento de Concepção do Projeto (DPC) - Fase de configuração do projeto, com ênfase especial na metodologia que estabeleça a adicionalidade e a sua linha de base. O projeto será considerado adicional se as emissões de GEE forem menores do que as que ocorreriam na sua ausência, já a linha de base é o cálculo para poder estipular o potencial de redução de emissões do projeto, levando em conta o nível de emissões sem o projeto.

$2^{\text {a }}$ Validação - Nessa fase, o participante deve contatar uma EOD (Entidade

\footnotetext{
${ }^{1}$ Os países que compõem o Anexo I são Alemanha, Austrália, Áustria, Bélgica, Bielorrússia, Bulgária, Canadá, Croácia, Chipre, República Tcheca, Dinamarca, Eslováquia, Eslovênia, Espanha, Estados Unidos, Estônia, Finlândia, França, Grécia, Hungria, Islândia, Irlanda, Itália, Japão, Letônia, Liechtenstein, Lituânia, Luxemburgo, Malta, Mônaco, Holanda, Nova Zelândia, Noruega, Polônia, Portugal, Reino Unido, Romênia, Rússia, Suécia, Suíça, Turquia, Ucrânia.
} 
Operacional Designada) para uma avaliação independente que possa confrontar o DPC e consequentemente promover melhorias se necessário.

$3^{a}$ Aprovação da Autoridade Nacional Designada - Corresponde à aprovação do projeto por parte do governo local. No Brasil a AND é a Comissão Interministerial de Mudança Global do Clima (CIMGC), que é composta por membros de distintos ministérios do governo.

$4^{a}$ Registro - A aceitação formal de um projeto como MDL é feita pelo Conselho Executivo ${ }^{2}$ após a fase de aprovação. O CE analisa toda a documentação enviada (o DPC), assim como os relatórios da EOD e da AND, e se tudo estiver de acordo será feito o registro do projeto.

$5^{a}$ Monitoramento - Após registro e implementação do projeto, começa a etapa de monitoramento que é realizada pelos próprios participantes, seguindo os planos estabelecidos no DCP. O monitoramento deve ser constante, incluindo o recolhimento e armazenamento de todos os dados necessários para os cálculos estabelecidos na metodologia, criando relatórios que serão submetidos à EOD para verificação (a menos que seja um projeto de pequena escala, essa EOD deverá ser diferente da que efetuou a validação do projeto).

$6^{a}$ Verificação e Certificação - Nessa etapa de verificação é feita uma auditoria periódica e independente por meio de outra EOD para que seja feita uma revisão dos cálculos e resultados apresentados pelo projeto no objetivo de redução das emissões dos GEEs. E, portanto, uma certificação é encaminhada por escrito ao CE, confirmando que em um determinado período o projeto foi capaz de atingir os objetivos da sua metodologia aplicada no DCP.

$7^{a}$ Emissão das RCEs - A certificação enviada ao Conselho Executivo comprova que os efeitos do projeto são reais, mensuráveis e de longo prazo, garantindo, portanto, a emissão das RCEs proporcional à quantidade reduzida de emissões de GEEs geradas pelo projeto. Essas são emitidas pelo CE e creditadas ao administrador do registro do MDL.

Portanto, observa-se que o processo de registro e aprovação de um projeto MDL é complexo, sendo também considerado lento e de custo relativamente alto. Para os investidores terem incentivos ainda assim em investir seu capital nesses projetos, um cenário favorável no mercado de carbono ${ }^{3}$, onde os preços dos certi-

\footnotetext{
${ }^{2}$ O Conselho Executivo é o órgão responsável por supervisionar o MDL, sob a autoridade da Convenção-Quadro das Nações Unidas sobre Mudança do Clima.

${ }^{3} \mathrm{~A}$ ideia por detrás desse sistema é que instituições ou governos que possuam um excesso de licenças de emissões possam vender a outras que tenham excedido sua capacidade de emissão, sendo o preço dessas licenças definido pelo mercado através da oferta e demanda. O mercado de carbono global pode ser dividido em dois tipos: os alinhados ao Protocolo de Quioto e os mercados voluntários (ou Não-
} 
ficados de emissões ou RCE's sejam atrativos, é de suma importância para o desenvolvimento das metas traçadas no Protocolo de Quioto.

\section{METODOLOGIA}

\section{Análise de correspondência}

As técnicas exploratórias de análise de correspondência são muito úteis quando se tem a intenção de trabalhar com variáveis que apresentam dados categóricos. É uma técnica de interdependência que permite flexibilidade nos tipos de dados que podem ser analisados. O único requisito para a análise de correspondência é uma tabela de contingência de entradas não-negativas (neste estudo, frequências derivadas de referências cruzadas de tipos de projetos de MDL e escala/status dos projetos).

A análise de correspondência se baseia em uma decomposição de valor singular de uma matriz de distâncias quiquadrado. A partir desta decomposição, tem-se valores e vetores próprios aplicados às matrizes de distância de linha e coluna. Estes, por sua vez, produzem as distâncias entre pontos para o mapeamento. $\mathrm{O}$ algoritmo deriva as distâncias entre os pontos e entre as categorias de linha e coluna, de maneira que as inter-relações entre elas sejam maximizadas.

No que se refere ao número máximo de dimensões para uma solução de análise de correspondência, este deve ser igual ao menor número de linhas menos uma ou o número de colunas menos uma. Neste estudo, como o número de linhas (ou seja, tipos de projetos) é 3 e o número de colunas (ou seja, escala/status) é 4, o número máximo de dimensões é 2 . Para determinar a dimensionalidade da solução, os valores próprios e a proporção acumulada de variância explicada pelas dimensões são examinadas.

Como no presente estudo está-se interessado em saber a intensidade da associação entre apenas duas variáveis categóricas (tipo de projeto de MDL e escala/ status do projeto) e suas categorias, utiliza-se a análise de correspondência bivariada. Esta técnica avalia a intensidade de associação a partir de uma tabela cruzada de dados, conhecida por tabela de contingência. Nesta tabela são dispostas, em cada célula, as frequências absolutas observadas para cada par de categorias das duas variáveis.

O presente estudo omitiu as equações e tabelas representativas da Análise de Correspondência por este método ser bem difundido na literatura especializada. Entretanto, seu conteúdo pode ser consultado em vários livros. Para maiores informações, ver Härdle e Simar (2014) e Favero e Belfiore (2017).

Quioto). O MDL se insere nesse primeiro cenário, permitindo a participação dos países em desenvolvimento. Nestes mercados, as Reduções Certificadas de Emissões (RCEs) podem ser negociadas e vendidas para os países do Anexo I, ajudando-os a cumprirem suas metas estabelecidas pelo protocolo. 


\section{Fonte e tratamento dos dados}

Todas as séries utilizadas no presente estudo são retiradas no Banco de Dados CDM/JI Pipeline da UNEP DTU e estão disponíveis para os anos de 2004 a 2019.

A variável tipo de projeto é formada por 3 categorias: energia, gás de aterro sanitário e reflorestamento. Energia engloba dados de energia hidrelétrica, eólica, biomassa e solar. São considerados todos os projetos brasileiros registrados e rejeitados, de grande e pequena escala, no período, totalizando 343 projetos.

Para a análise de correspondência, se o tipo de projeto é de energia, ele recebe o valor 1; gás de aterro sanitário - valor 2; e reflorestamento - valor 3.

A variável escala/status é formada da seguinte maneira: se é larga escala e registrado, o projeto recebe valor 1; larga escala e rejeitado - valor 2; pequena escala e registrado - valor 3; e pequena escala e rejeitado - valor 4.

\section{RESULTADOS E DISCUSSÃO}

\section{Caracterização dos projetos de MDL}

Em novembro de 2004, o Brasil registrou o primeiro projeto de MDL, se tornando pioneiro no desenvolvimento deste tipo de projeto. Desde então, até setembro de 2019, o país possui 343 projetos registrados na UNFCCC, representando $5 \%$ do total mundial de 7.808 projetos, sendo o terceiro país com mais projetos registrados, atrás da China com 3.764 (48\%) e da Índia com 1.669 (21\%) como mostra a Figura 1.

Figura 1: Número total de projetos MDL registrados no mundo, 2019

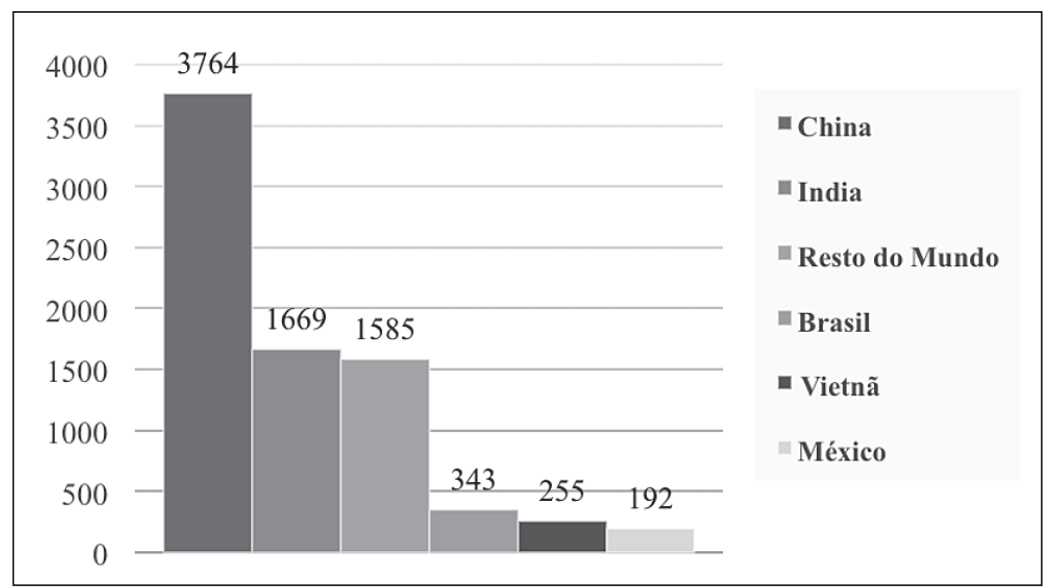

Fonte: Elaboração própria a partir do Banco de Dados CDM/JI Pipeline da UNEP DTU. 
Isso mostra que apesar de o país ter papel relevante na participação mundial com relação ao número de projetos registrados, ainda está longe de atingir seu potencial esperado. Uma soma de fatores, como a ausência de capacitação de profissionais para trabalhar com tais projetos, a falta de incentivo e divulgação por parte do governo, além da insegurança dos investidores, faz com que esse número seja ainda pequeno comparado com os de China e Índia. Segundo Miguez (2008), um dos principais motivos para o sucesso destes dois últimos países, se comparado com o Brasil, é que esses possuem uma matriz energética com significativa dependência do consumo de combustíveis fósseis, especialmente o carvão mineral. Este fato faz com que ocorra uma maior lacuna para viabilização de projetos que reduzam as emissões de GEE do que no Brasil, que possui uma matriz energética considerada mais limpa.

$\mathrm{Na}$ Figura 2, pode-se observar a distribuição dos projetos de MDL brasileiros registrados de acordo com sua escala. Os projetos de larga escala caracterizam-se pelo fato de serem ilimitados em relação à sua extensão, onde as metodologias aplicadas a tais projetos podem ou ser elaboradas pelos proponentes ou submetidas a metodologias que já foram aprovadas.

Os projetos de pequena escala, por sua vez, foram feitos para que empresas de menor porte também consigam, de forma equivalente, viabilizar suas atividades de MDL. A principal característica desses projetos é a limitação do seu tamanho, já estabelecido nas metodologias que foram criadas pelo Conselho Executivo e disponibilizadas ao público, com o intuito principal de reduzir custos e facilitar que o desenvolvedor do projeto apenas se ajuste a elas.

Figura 2: Percentual de projetos por escala

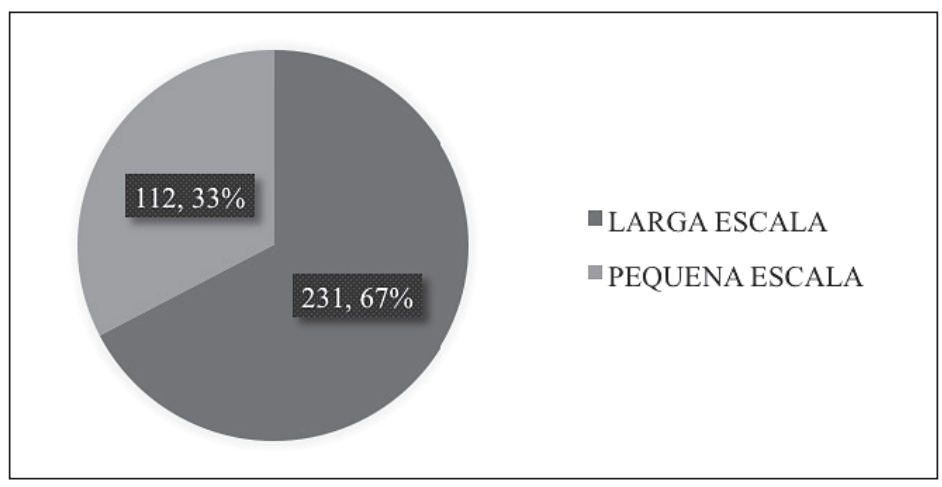

Fonte: Elaboração própria a partir do Banco de Dados CDM/JI Pipeline da UNEP DTU.

O número de projetos de larga escala destaca-se perante os projetos de pequena escala, e isso pode ser explicado pelo fato desses projetos terem a capacidade de gerar um número alto de RCE's, tendo assim uma perspectiva maior de beneficiamento financeiro. Boyd (2009) faz uma crítica ao MDL e diz que a complexidade e os altos custos de transação associados aos processos do mecanismo fazem com 
que haja um grande impedimento no desenvolvimento de projetos de pequena escala. E que, mesmo com as simplificações elaboradas pela CQNUMC, a compensação de projetos de carbono privados do mercado voluntário ainda é muito mais rápida e simples, mas, em contrapartida, são projetos considerados mais arriscados, uma vez que não possuem uma supervisão regulatória padronizada.

A Figura 3 ratifica principalmente a falta de entendimento e capacitação do Brasil como um todo para conseguir registrar um projeto de MDL. Tem-se um número extremamente alto de projetos classificados como rejeitados, retirados ou com a validação interrompida, maior até que o número de projetos registrados. Isso quer dizer que muitos projetos ou não conseguem passar pelas sete fases de avaliação e monitoramento ou foram retirados devido à inviabilidade econômica não esperada.

Figura 3: Status dos projetos MDL no Brasil (\%)

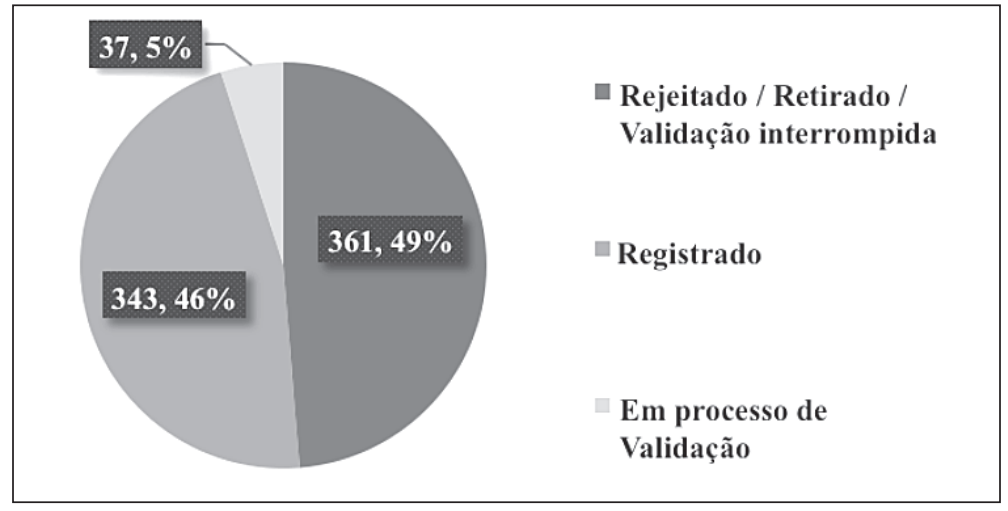

Fonte: Elaboração própria a partir do Banco de Dados CDM/JI Pipeline da UNEP DTU.

O alto número de projetos rejeitados questiona a qualidade do processo de validação, principalmente devido a preocupações com relação ao desempenho de algumas EODs no que diz respeito à sua competência em desempenhar suas funções de validação e verificação em conformidade com os requisitos do MDL (Schneider, 2007).

Em termos da distribuição geográfica das atividades aprovadas no Brasil, tem-se que a maioria delas está concentrada na Região Sudeste (38\%), com destaque para os estados de São Paulo e Minas Gerais. Isso já era esperado tendo em vista que o Sudeste é a região mais desenvolvida do país, onde o leque de possibilidades é muito maior que em outras regiões. As Regiões Sul, Nordeste e Centro-Oeste, com, respectivamente, $22 \%, 18 \%$ e $17 \%$, vem tendo também participações significativas no cenário. Por último, tem-se a Região Norte com apenas $5 \%$ do total de projetos registrados conforme mostra a Figura 4. É importante salientar que o total de projetos por estado é maior que o total de projetos registrados porque um projeto pode expandir sua atividade para mais de um estado. 
Figura 4: Distribuição de projetos por região no Brasil

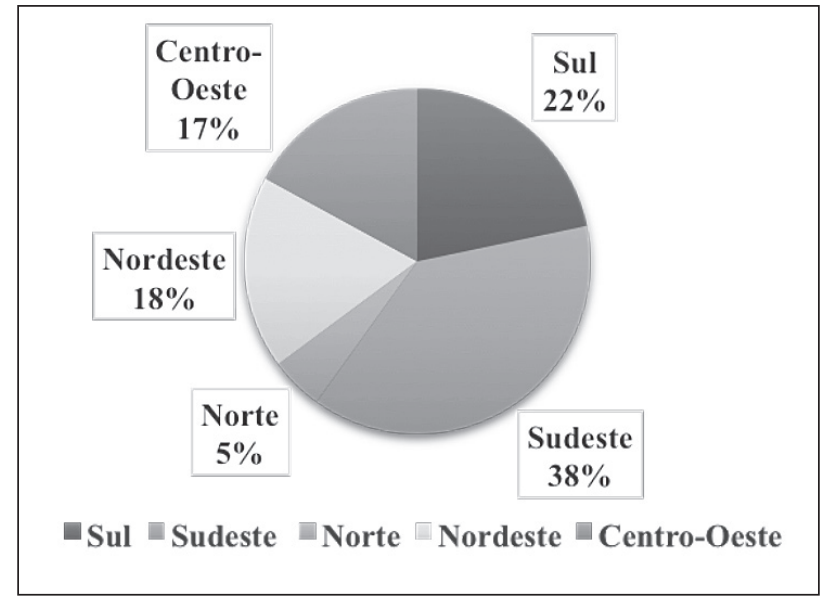

Fonte: Elaboração própria a partir do Banco de Dados CDM/JI Pipeline da UNEP DTU.

Quanto a distribuição dos projetos brasileiros, por tipo, registrados até setembro de 2019, tem-se que os de energia hidrelétrica lideram o ranking, com 95 projetos $(27,7 \%)$. Suas atividades estão distribuídas em microcentrais, pequenas centrais e grandes centrais. Em segundo, tem-se os projetos de prevenção de metano ou biogás, com 65 (19\%), sendo relevantes as atividades com suinocultura e tratamento de águas residuais. Em seguida, pode-se observar energia eólica, com 57 (16,6\%); gás de aterro sanitário, com 53 (15,5\%); e energia de biomassa com 48 projetos $(14 \%)$. A Tabela 1 ilustra os resultados.

Tabela 1: Distribuição de atividades de projetos brasileiros por tipo de projeto MDL registrados

\begin{tabular}{|c|c|c|c|c|}
\hline \multirow{2}{*}{ Tipos de Projeto } & \multirow{2}{*}{$\begin{array}{c}\text { Quant. de } \\
\text { projetos }\end{array}$} & \multirow{2}{*}{$\begin{array}{l}\text { \% em } \\
\text { relação ao } \\
\text { total }\end{array}$} & \multicolumn{2}{|c|}{$\begin{array}{c}\text { Redução esperada acumulada } \\
\text { de GEE para } 2030\end{array}$} \\
\hline & & & $\mathrm{ktCO}_{2} \mathrm{eq}$ & $\begin{array}{c}\% \text { em relação } \\
\text { ao total }\end{array}$ \\
\hline Energia Hidrelétrica & 95 & $27,7 \%$ & $238.377,73$ & $28,73 \%$ \\
\hline Prevenção de metano & 65 & $19,0 \%$ & $38.853,11$ & $4,68 \%$ \\
\hline Energia Eólica & 57 & $16,6 \%$ & $103.657,69$ & $12,49 \%$ \\
\hline Gás de aterro sanitário & 53 & $15,5 \%$ & $225.130,28$ & $27,13 \%$ \\
\hline Energia de Biomassa & 48 & $14,0 \%$ & $51.641,46$ & $6,22 \%$ \\
\hline Mudança de combustível & 6 & $1,7 \%$ & $4.742,54$ & $0,57 \%$ \\
\hline Decomposição de $\mathrm{N}_{2} \mathrm{O}$ & 5 & $1,5 \%$ & $133.912,13$ & $16,14 \%$ \\
\hline $\begin{array}{l}\text { Geração própria de energia } \\
\text { eficiente }\end{array}$ & 3 & $0,9 \%$ & $2.779,34$ & $0,33 \%$ \\
\hline $\begin{array}{l}\text { Redução na fuga de } \\
\text { combustíveis: }\end{array}$ & 3 & $0,9 \%$ & $4.651,22$ & $0,56 \%$ \\
\hline
\end{tabular}




\begin{tabular}{lccrr}
\hline Reflorestamento & 3 & $0,9 \%$ & $15.706,67$ & $1,89 \%$ \\
Substituição de PFCs e SF6 & 2 & $0,6 \%$ & $6.942,61$ & $0,84 \%$ \\
Captura do $\mathrm{CO}_{2}$ & 1 & $0,3 \%$ & 324,01 & $0,04 \%$ \\
Distribuição de energia & 1 & $0,3 \%$ & $2.937,40$ & $0,35 \%$ \\
Energia Solar & 1 & $0,3 \%$ & 16,85 & $0,00 \%$ \\
\hline TOTAL & 343 & $100 \%$ & $829.673,04$ & $100 \%$ \\
\hline
\end{tabular}

Fonte: Elaboração própria a partir do Banco de Dados CDM/JI Pipeline da UNEP DTU.

Os tipos de projetos que apresentaram melhor percentual de redução esperada de GEE acumulada foram os de energia hidrelétrica, gás de aterro sanitário, decomposição de $\mathrm{N}_{2} \mathrm{O}$ e energia eólica que juntos representam $84,5 \%$ do total de emissões de $\mathrm{CO}_{2}$ eq a serem reduzidas até o ano de 2030. A previsão é que até 2030 esses 343 projetos consigam reduzir cerca de $829.673,04$ ktCO 2 eq.

A partir da Figura 5, pode-se observar a distribuição dos registros de projetos de MDL por ano e notar que se tem discrepâncias significativas nos anos de 2006 e 2012. Nestes anos, ocorre um número alto de projetos registrados no Brasil (primeira fase do Protocolo de Quioto). É notável, também, a queda significativa no segundo período de compromisso do Protocolo (2013-2020).

Figura 5: Número de projetos MDL registrados por ano no Brasil

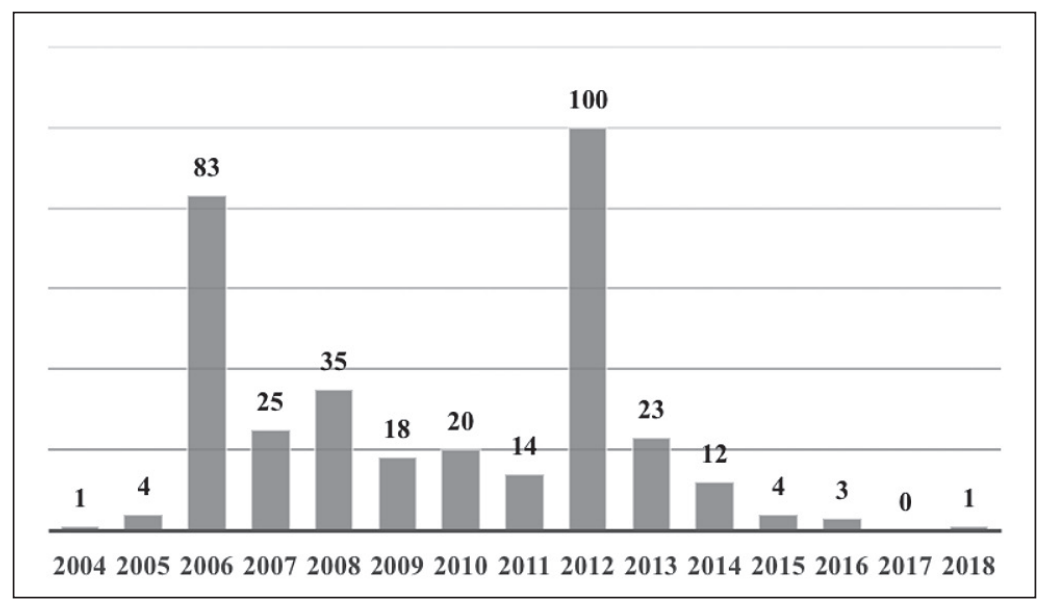

Fonte: Elaboração própria a partir do Banco de Dados CDM/JI Pipeline da UNEP DTU.

Durante os anos de 2007 a 2011, percebe-se uma queda grande no número de projetos, se comparado com o ano de 2006, quando foram registrados 83 projetos. Segundo Chaves (2016), essa queda se deu pela incerteza acerca da continuidade do Protocolo pós-2012 e, também, pela crise econômica mundial de 2008.

Em 2012, por ser o último ano da primeira fase do Protocolo, ocorre um surpreendente crescimento do número de projetos registrados, número recorde no país, com 100 registros. Assim, os países que não tinham alcançado a meta prevista de 
redução de emissões estavam na corrida contra o tempo para que através do MDL conseguissem adquirir as RCE's necessárias para o cumprimento da meta. Pelo lado dos desenvolvedores de projetos, houve uma preocupação em registrar suas atividades até o final do ano, já que as incertezas do prolongamento do tratado eram cada vez maiores.

A aprovação da Emenda de Doha, que foi realizada no final do ano de 2012, estabeleceu novos compromissos de redução dos países desenvolvidos para o segundo período. Ainda assim, observam-se números insignificantes de projetos registrados no Brasil nesse período. Isso ocorre devido ao fato de a emenda não ter entrado em vigor até o presente momento, já que, para tal, conforme previsto no artigo 20, parágrafo 4, é necessário que pelo menos três quartos das Partes do Protocolo de Quioto, ou seja, 144 partes, depositem seu instrumento de aceitação. Entretanto, tem-se que 134 partes o fizeram até o dia 18 de outubro de 2019. Países importantes como EUA, Rússia, Austrália, Japão, Canadá e Nova Zelândia ainda não assinaram o acordo para o segundo período de compromisso, com a crítica de que países em desenvolvimento, como China, Brasil, Índia, Indonésia e México, também deveriam assumir compromissos de redução, já que são grandes emissores de GEE.

Outro fator que contribuiu para o fracasso no desenvolvimento de novos projetos nesse período foi a queda dos preços das RCE's ${ }^{4}$ a partir do ano de 2012. Esta queda fez com que a União Europeia adotasse, na fase III (2013-2020) do EU ETS, a restrição de participar no seu mercado apenas os projetos registrados em países da lista de "menos desenvolvidos". Esta medida fez com que os investimentos em MDL no Brasil caíssem, seguindo a tendência mundial, já que a maioria desses projetos não renderiam retorno esperado. Assim sendo, o número de projetos que buscavam registro caiu e muitos projetos já registrados deixaram de operar (Mori-Clement e Bednar-Friedl, 2019).

O MDL possui um futuro incerto para o período pós-2020. Muito se tem discutido e ainda muitas incertezas fazem parte dessas discussões, pois pouco se tem avançado. Entretanto, é importante observar que com a $21^{a}$ Conferência entre as Partes (COP 21), ocorrida em Paris em 2015, e com aquelas que ocorreram posteriormente, o objetivo ainda continua sendo fazer com que todas as nações empreendam esforços para conter o aumento da temperatura global neste século, limitando a elevação da temperatura abaixo dos $2{ }^{\circ} \mathrm{C}$, preferencialmente restringindo-a em $1,5^{\circ} \mathrm{C}$, além de reforçar a capacidade dos países em atender a esse desafio, sendo que, para isso, a colaboração de todos os países é de extrema importância (Brasil, 2019).

\footnotetext{
${ }^{4}$ Os principais determinantes para o colapso de preço das RCE's foram: crise na Europa e consequente queda nas atividades industriais; e excesso de licenças de emissão no EU ETS, principal mercado na demanda das RCE's (Yu, Grady, Knipp, 2012).
} 


\section{Análise de Correspondência}

Um dos objetivos do presente estudo é verificar a existência de associação entre o tipo de projeto de MDL e sua escala/status. Para fazer isso, utiliza-se uma análise de correspondência simples.

Para verificar se os dados se ajustam a este tipo de análise, faz-se necessário calcular o valor do quiquadrado para a amostra selecionada. Este valor é igual a 33,96, significativo a $1 \%$ de probabilidade. A Tabela 2 ilustra os resultados encontrados.

Tabela 2: Resultado do teste de quiquadrado para verificação de associação entre tipo de projeto e escala/status

\begin{tabular}{lcc}
\hline & Valor & Significância \\
\hline Valor do Quiquadrado & 33,963 & 0,000 \\
Razão de Verossimilhança & 47,314 & 0,000 \\
Número de casos válidos & 300 & \\
\hline
\end{tabular}

Fonte: Resultados da pesquisa.

Além de avaliar associação significativa entre as variáveis, deve-se também estudar a relação de dependência entre cada par de categorias. A Tabela 3 permite que esta análise seja elaborada e mostra, para cada um dos casos, as frequências absolutas observadas e esperadas, os resíduos, os resíduos padronizados e os resíduos padronizados ajustados, bem como os valores totais em linha e em coluna de frequências absolutas e observadas que, obviamente, são iguais.

Tabela 3: Frequências e resíduos para cada tipo e escala de projeto

\begin{tabular}{ll|rrrrr}
\hline & & \multicolumn{6}{c|}{ ESCALA } & \multirow{2}{*}{ Total } \\
\cline { 3 - 6 } & & LRG & LRE & PRG & PRE & \\
\hline \multirow{4}{*}{ Energia } & Freq. observada & 139 & 36 & 62 & 7 & 244 \\
& Freq. esperada & 157,8 & 29,3 & 51,2 & 5,7 & 244,0 \\
& Resíduos & $-18,8$ & 6,7 & 10,8 & 1,3 & \\
& Res. padronizados & $-1,5$ & 1,2 & 1,5 & 0,5 & \\
& Res. ajustados & $-5,8$ & 3,1 & 0,39 & 1,3 & \\
\hline \multirow{5}{*}{ Gás } & Freq. observada & 52 & 0 & 1 & 0 & 53 \\
\cline { 2 - 5 } & Freq. esperada & 34,3 & 6,4 & 11,1 & 1,2 & 53,0 \\
& Resíduos & 17,7 & $-6,4$ & $-10,1$ & $-1,2$ & \\
& Res. padronizados & 3,0 & $-2,5$ & $-3,0$ & $-1,1$ & \\
& Res. ajustados & 5,6 & $-3,0$ & $-3,8$ & $-1,2$ & \\
\hline \multirow{5}{*}{ Reflor. } & Freq. observada & 3 & 0 & 0 & 0 & 3 \\
& Freq. esperada & 1,9 & 0,4 & 0,6 & 0,1 & 3,0 \\
& Resíduos & 1,1 & $-0,4$ & $-0,6$ & $-0,1$ & \\
& Res. padronizados & 0,8 & $-0,6$ & $-0,8$ & $-0,3$ & \\
& Res. ajustados & 1,3 & $-0,6$ & $-0,9$ & $-0,3$ & \\
\hline \multirow{2}{*}{ Total } & Freq. observada & 194 & 36 & 63 & 7 & 300 \\
& Freq. esperada & 194,0 & 36,0 & 63,0 & 7,0 & 300,0 \\
\hline
\end{tabular}

Fonte: Resultados da pesquisa.

Nota: $L R G=$ projetos de larga escala registrados; $L R E=$ projetos de larga escala rejeitados; $P R G=$ projetos de pequena escala registrados; e PRE = projetos de pequena escala rejeitados. 
Pode-se verificar, por meio da Tabela 3, que enquanto há maior proporção de projetos de MDL de energia, existe também uma quantidade maior de projetos de energia de grande escala registrados. Para o tipo de projeto de MDL relacionado à energia, os resíduos são maiores para categoria projetos pequenos registrados, o que indica que as diferenças entre as frequências absolutas observadas e esperadas são maiores. Além disso, como o valor do resíduo padronizado ajustado é igual a 3,9 (positivo e maior que 1,96), pode-se concluir que há dependência entre as categorias tipos de projetos de MDL e escala/status. O mesmo pode ser observado para a categoria gás de aterro sanitário e projetos de larga escala registrados. Para reflorestamento, não se observou associação estatisticamente significativa, pois nenhum desvio ajustado foi superior a 1,96 .

Pela Tabela 3, observa-se também que todos os projetos de gás de aterro sanitário foram registrados, com 52 de grande escala e apenas 1 de pequena escala. $\mathrm{O}$ mesmo ocorre com projetos de reflorestamento. Dos 3 projetos feitos, os 3 eram de grande escala e foram registrados.

Após os testes supracitados, os resultados da análise de correspondência entre as duas categorias analisadas podem ser obtidos. Observa-se que foram encontradas duas dimensões (significam combinações de valores de correspondência das duas categorias analisadas) e a decomposição inercial para as duas dimensões pode ser visualizada na Tabela 4 .

Tabela 4: Decomposição inercial para as duas dimensões

\begin{tabular}{cccccc}
\hline & & & \multicolumn{2}{c}{ Proporção da Inércia } \\
\cline { 5 - 6 } Dimensão & Valor & Inércia & Sig. & Inércia principal total & Cumulativa \\
& & & & & 1,00 \\
\hline 1 & 0,34 & 0,11 & & 0,00 & 1,00 \\
2 & 0,003 & 0,00 & & 1,00 & 1,00 \\
Total & & 0,11 & 0,00 & & 1,00 \\
\hline
\end{tabular}

Fonte: Resultados da pesquisa.

Os resultados da Tabela 4 mostram que a dimensão 1 explica 100\% da inércia principal total e quanto maior for esta inércia, maior será a associação entre as categorias e mais adequada torna-se a análise de correspondência.

Após a verificação de todos os requisitos necessários para a confecção da análise de correspondência, pode-se construir o mapa perceptual que é a principal contribuição deste tipo de análise. A Figura 6 ilustra os resultados encontrados. 
Figura 6: Mapa perceptual para tipo de projeto de MDL e escala

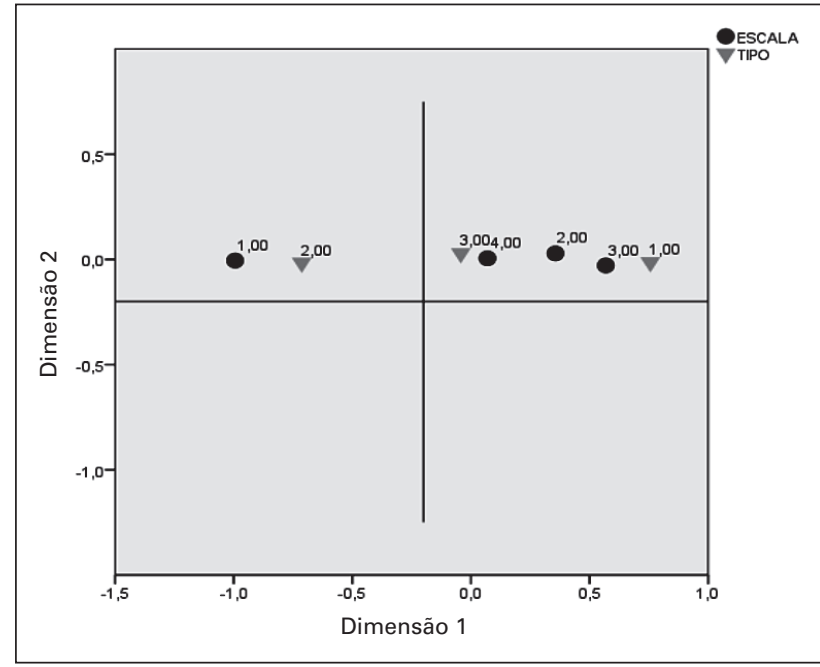

Fonte: Resultados da pesquisa.

Por meio da Figura 6, pode-se observar que projetos de MDL voltados para gás de aterro sanitário apresentam forte associação com projetos de grande escala que foram registrados. Da mesma forma, projetos de energia estão estreitamente ligados com pequena escala registrados. As associações para reflorestamento não foram conclusivas, pois na Tabela 3 observa-se que reflorestamento não possui nenhuma associação, estatisticamente significativa, com escala/status. Isso pode ter ocorrido dada a peculiaridade de ter-se apenas 3 projetos de reflorestamento dentro da amostra selecionada.

É interessante notar que os resultados encontrados para energia no presente estudo são corroborados pelos encontrados por Góes et al. (2018). Foi feita uma análise documental de 47 Documentos de Concepção do Projeto (DCP) de todos os projetos de energia eólica no Nordeste, registrados pelo Conselho Executivo do MDL até maio de 2016. Os resultados mostram que a maioria dos projetos é de pequeno porte, assim como o observado no presente estudo.

\section{CONSIDERAÇÕES FINAIS}

Este estudo buscou analisar a contribuição, a participação e o desenvolvimento dos projetos de Mecanismo de Desenvolvimento Limpo no Brasil, até setembro de 2019, englobando praticamente os dois períodos de vigência do Protocolo de Quioto.

É importante ressaltar aqui a importância que este mecanismo ganhou durante a primeira fase de cumprimento de meta do Protocolo de Quioto. O Brasil avançou muito em número e tipo de projeto registrado neste período. 
Outro resultado importante é que, por meio da análise de correspondência, observa-se que a maioria dos projetos registrados se refere ao setor de energia (projeto registrado de pequena escala). Em seguida, tem-se projetos de MDL voltados para gás de aterro sanitário e estes possuem associação com projetos de grande escala registrados. Estes resultados mostram a importância da escala no sucesso da aprovação dos projetos registrados. Projetos de energia, por exemplo, têm mais chances de serem aprovados se forem de pequena escala. Isso é interessante, já que a estrutura do MDL foi originalmente concebida para projetos de grande porte. A criação de modalidades para pequena escala tem a finalidade de tornar os procedimentos mais simples e, também, reduzir os custos dos projetos.

Conclui-se que a criação do MDL foi um avanço importante, principalmente por ter sido um dos principais mecanismos implantados pelo Protocolo. Ele também se tornou um marco histórico internacional, pois é uma ferramenta de caráter inovador na contribuição à mitigação das mudanças climáticas.

Contudo, apesar de sua importância ser reconhecida globalmente, observa-se que o mecanismo foi se enfraquecendo com o passar do tempo. O fato é que no Brasil houve uma queda considerável no desenvolvimento de projetos no segundo período de compromisso, principalmente devido à insegurança especulativa em torno do futuro do mecanismo e da instabilidade do mercado mundial de carbono.

\section{REFERÊNCIAS BIBLIOGRÁFICAS}

BAYER, Patrick; URPELAINEN, Johannes; WALLACE, Jeremy. Who uses the Clean Development Mechanism? An empirical analysis of projects in Chinese provinces. Global environmental change, v. 23, n. 2, p. 512-521, 2013.

BITHAS, K. Sustainability and externalities: Is the internalization of externalities a sufficient condition for sustainability? Ecological Economics, v.70, p.1703-1706, 2011.

BOYD, Emily et al. Reforma do MDL para o desenvolvimento sustentável: lições aprendidas e futuro das políticas. Ciência e Política Ambiental, v. 12, n. 7, p. 820-831, 2009.

BRASIL. Banco Central do Brasil. Boletim Responsabilidade Social e Ambiental do Sistema Financeiro. Ano 5, $\mathrm{n}^{\circ}$ 53, dezembro de 2010.

BRASIL. Ministério da Ciência, Tecnologia, Inovações e Comunicações - MCTIC. Autoridade Nacional Designada para o MDL. 2019. Disponível em: <https://www.mctic.gov.br/mctic/opencms/ ciencia/SEPED/clima/cimgc/Comissao_Interministerial_de_Mudanca_Global_do_Clima_CIMGC.html >. Acesso em: agosto de 2019.

BRASIL. Ministério do Meio Ambiente - MMA. Acordo de Paris. 2019. Disponível em: <https://www. mma.gov.br/clima/convencao-das-nacoes-unidas/acordo-de-paris>. Acesso em: outubro de 2019.

BRASIL. Ministério do Meio Ambiente - MMA. Protocolo de Kyoto. 2019. Disponível em: <http:// www.mma.gov.br/clima/convencao-das-nacoes-unidas/protocolo-de-Kyoto $>$. Acesso em: abril de 2019.

CAPOOR, Karan; AMBROSI, Philippe. Estado e tendências do mercado de carbono 2009. New York: World Bank Report, 2009.

CHAMBERS, Jeffrey Q. et al. Danos em árvores, relações alométricas e produção primária líquida acima do solo na floresta central da Amazônia. Forest Ecology and Management, v. 152, n. 1-3, p. 73-84, 2000.

CHAVES, Paulo Jair Soares. Mercado de carbono: uma nova realidade. 2016. Trabalho de Conclusão 
de Curso (Ciências Econômicas) - Universidade Regional do Noroeste do Estado do Rio Grande do SUL - UNIJUÍ, IJUÍ, 2016.

COMISSÃO MUNDIAL SOBRE MEIO AMBIENTE E DESENVOLVIMENTO (CMMAD). Nosso Futuro Comum. Rio de Janeiro: Fundação Getúlio Vargas, 1988, p.46.

DE GODOY, Sara Gurfinkel Marques; SAES, Maria Sylvia Macchione. Cap-and-Trade e projetos de redução de emissões: comparativo entre mercados de carbono, evolução e desenvolvimento. Ambiente \& Sociedade, v. 18, n. 1, p. 141-160, 2015.

DECHEZLEPRÊTRE, Antoine; GLACHANT, Matthieu; MÉNIÈRE, Yann. Technology transfer by CDM projects: A comparison of Brazil, China, India and Mexico. Energy policy, v. 37, n. 2, p. 703-711, 2009.

ELLIS, Jane; WINKLERD, Harald; CORFEE-MORLOTA, Jan; GAGNON-LEBRUNC, Frederic. CDM: Taking stock and looking forward. Energy policy, v. 35, n. 1, p. 15-28, 2007.

FAVERO, L. P.; BELFIORE, P. Manual de Análise de Dados: Estatística e Modelagem Multivariada com Excel®, SPSS ${ }^{\circledR}$ e Stata ${ }^{\circledR}$. GEN LTC, $1^{\text {a }}$ Ed., 2017. 2049 p.

FIGUERES, Christiana. Sectoral CDM: Opening the CDM to the Yet Unrealized Goal of Sustainable Development. International Journal of Sustainable Development Law \& Policy. v. 2, n. 1, jan. 2006.

GÓES, M. F. B.; ANDRADE, J. C. A.; SILVA, M. S.; SANTANA, A. C. projetos de MDL de Energia Eólica no Nordeste do Brasil: perfil e co-benefícios declarados. RGSA, 12(2), 71-89, 2018.

GUILLEN, Chana Michelli. Contribuições de atividades de mecanismo de desenvolvimento limpo (MDL) ao desenvolvimento sustentável do Brasil. Dissertação (Mestrado em Administração) Universidade Federal do Rio Grande do Sul, Porto Alegre, 2010.

HARDI, Peter; ZDAN, T. J. The dashboard of sustainability. Winnipeg: IISD, v. 100, p. 46-55, 2000.

HÄRDLE, W. K.; SIMAR, L. Applied Multivariate Statistical Analysis. Springer: 4a ed., 2014. 580 p.

LAZARO, L. L. B.; GREMAUD, A. P. Contribuição para o desenvolvimento sustentável dos projetos de Mecanismo de Desenvolvimento Limpo na América Latina. Revista Organizações e Sociedade, v. 24, n. 80, p. 53-72, 2017.

MAGALHÃES, A. S. Economia de baixo carbono no Brasil: alternativas de políticas e custos de redução de emissões de gases de efeito estufa. Centro de Desenvolvimento e Planejamento Regional/ Faculdade de Ciências Econômicas, Universidade Federal de Minas Gerais, Belo Horizonte, 2013.

MARTINS, A. R. P. Desenvolvimento Sustentável: uma análise das limitações do índice de desenvolvimento humano para refletir a sustentabilidade ambiental. Rio de Janeiro, 2006, 127 f. Dissertação (Mestrado) - Engenharia de Produção, Universidade Federal Fluminense, Niterói, 2006.

MIGUEZ, José D. G. Ações de Mitigação das emissões no Brasil. In: Plenarium, v.5, n.5, 2008.

MONTGOMERY, W. David. Markets in licenses and efficient pollution control programs. Journal of economic theory, v. 5, n. 3, p. 395-418, 1972.

MORI-CLEMENT, Yadira; BEDNAR-FRIEDL, Birgit. Do Clean Development Mechanism projects generate local employment? Testing for sectoral effects across Brazilian municipalities. Ecological economics, v. 157, p. 47-60, 2019.

PASINI, Kristian Brito; DE ANDRADE SPÍNOLA, Carolina. Projetos de Mecanismo de Desenvolvimento Limpo (MDL): Motivações, Barreiras e Contribuição para Promoção de Tecnologias Mais Limpas. XXXV Encontro da ANPAD. Rio de Janeiro, 2011

PEARCE, D.W.; TURNER, R.K. The Optimal Level of Pollution. Economics of natural resources and the environment. The Johns Hopkins University Press Baltimore, 1990.

PRESCOTT-ALLEN, Robert. Barometer of Sustainability: Measuring and communicating wellbeing and sustainable development. IUCN, Gland, CH, 1997.

REDCLIFT, Michael. The meaning of sustainable development. Geoforum, v. 23, n. 3, p. 395-403, 1992.

REES, William; WACKERNAGEL, Mathis; TESTEMALE, Phil. Nossa pegada ecológica: Reduzindo o impacto humano na terra. Ilha Gabriola, BC: New Society Publishers, 1996.

SACHS, Ignacy. Estratégias de transição para o século XXI: desenvolvimento e meio ambiente. Studio Nobel, Fundação do Desenvolvimento Administrativo, 1993. 
SACHS, Ignacy. Meio ambiente e desenvolvimento: estratégias de harmonização. Meio Ambiente, Desenvolvimento e Subdesenvolvimento, v. 1, p. 55-85, 1975.

SACHS, Ignacy. Recursos, emprego e financiamento do desenvolvimento: produzir sem destruir: o caso do Brasil. Brasiliense, 1990.

SANTIN, Maria Fernanda Cavaliéri de Lima. Os impactos da demanda por crédito de carbono sobre o mercado de Certificações de Reduções de Emissões no Brasil, no âmbito do Protocolo de Kyoto. Dissertação de Mestrado em Economia. Pontifícia Universidade Católica do Rio Grande do Sul. Porto Alegre, 2007.

SCHNEIDER, Lambert. Is the CDM fulfilling its environmental and sustainable development objectives? An evaluation of the CDM and options for improvement. Öko-Institut for Applied Ecology, Berlin, v. 248, p. 6, 2007.

SOUZA, Maria Cristina Oliveira; CORAZZA, Rosana Icassatti. Do Protocolo Kyoto ao Acordo de Paris: uma análise das mudanças no regime climático global a partir do estudo da evolução de perfis de emissões de gases de efeito estufa. Desenvolvimento e Meio Ambiente, v. 42, 2017.

SPASH, C.L. Economics, ethics, and long-term environmental damages. Environmental Ethics 15 (2), p. 117-132, 1993.

SUTTER, Christoph; PARREÑO, Juan Carlos. Does the current Clean Development Mechanism (CDM) deliver its sustainable development claim? An analysis of officially registered CDM projects. Climatic change, v. 84, n. 1, p. 75-90, 2007.

VAN BELLEN, H. M. Indicadores de sustentabilidade: um levantamento dos principais sistemas de avaliação. Cad. EBAPE.BR, v. 2, n. 1, p.1-14, mar. 2004.

YU, Fei; GRADY, Patrick; KNIPP, Robert. Regulatory Stringency in Issuing Certified Emission Reductions and Price Effects in Secondary Markets. University Library of Munich, Germany. 2012. 